\title{
A escuta participante como procedimento de pesquisa do sagrado enunciante $^{1}$
}

\author{
José Francisco Miguel Henriques Bairrão \\ Universidade de São Paulo - Ribeirão Preto
}

\begin{abstract}
Resumo
Ao aprofundar a análise dos textos “sociais” de Freud descobre-se que, em vez de aplicações da psicanálise ao coletivo, são prolongamentos da metapsicologia, com elevada relevância clínica e, tomados isoladamente, acentuada pobreza enquanto construtos psicossociais. Este resultado deve entender-se como preâmbulo à continuação da crítica numa direção complementar: o resgate da dimensão inerentemente social dos conceitos psicanalíticos aparentemente ligados, com exclusividade, a aspectos clínicos ou metapsicológicos. Fazê-lo abre a perspectiva de desenvolver uma psicanálise socialmente interventiva, sem prejuízo do rigor técnico e epistemológico. O eixo que o possibilita prende-se ao conceito de sujeito, não mais confundido com indivíduo nem centrado no eu. O transe, tão presente em cultos extáticos brasileiros, constitui-se numa oportunidade para verificar esta hipótese. No transe, o Outro se enuncia em primeira pessoa e a sua natureza semiótica, longe de excluir a sua dimensão psíquica, a inclui, constituindo-se em plataforma segura para uma abordagem pública e social do inconsciente.
\end{abstract}

Palavras-chave: transe; método etnográfico; psicologia e religiões; psicologia social psicanalítica; sincretismo

\begin{abstract}
Participating listening as a research's procedure of the utterer holiness. Deepening the analysis of Freud's social texts, we discover that, instead of mere psychoanalytic applications to the collective, they are prolongations of metapsychological boundaries, clinically relevant and, taken separately, accentuated poverty while psycho-social constructs. This result must be understood as a preamble to the continuation of the critic in a complementary direction: the rescue of the inherently social dimension presents in psychoanalytical concepts, just in appearance exclusively linked with clinical or metapsychological features. Doing it opens the perspective of developing a socially interventive psychoanalysis, without decrease of precision. The axis that enables it is linked with the concept of self, no more confused with the single person neither centered in the I. Trance, so present at ecstatic Brazilian cults, constitute an opportunity to verify this hypothesis. At trance, the Other enunciates itself in first person and its semiotic nature, far from excluding its psychic dimension, includes it, constituting a secure platform for a public and social approaching of the unconscious.

Keywords: trance; ethnographic method; psychology and religions; psychoanalytical social psychology; syncretism
\end{abstract}

\section{Psicanálise contemporânea e transformação social}

É habitual reduzir a psicologia social psicanalítica aos escritos freudianos cujo conteúdo, à primeira vista, se prende a aspectos da cultura e do funcionamento grupal. Mas é pouco profícuo supor uma teoria social psicanalítica separada da clínica.

Os enunciados de Freud sobre o aparelho psíquico podem ser interpretados em termos puramente epistemológicos, sem a obrigatoriedade de concebê-los como coisas existentes em psiquismos individuais.
A segunda tópica, por exemplo, inclui elementos que transcendem o psiquismo e a individualidade, como o corpo, a realidade, o papel dos outros na constituição do eu, as gerações anteriores e a moralidade.

Porém, a ilusão psicológica do indivíduo afetou a leitura feita pelos psicólogos do que poderiam ser e onde estariam, na obra de Freud, as contribuições psicanalíticas para uma psicologia social (não obstante as dificuldades de constituição de uma ciência psíquica isolada).

No caso da psicologia social, talvez o principal transtorno causado pela leitura realista de Freud, o achatamento dos seus modelos heurísticos em descrições objetivas de uma 
suposta realidade psíquica, seja o retalhamento da psicanálise em fatias, cada uma delas dedicada a um setor da realidade. Ora, não cabe supor uma teoria social psicanalítica isolada da dimensão clínica e dissociável da metapsicologia.

Não é este o caso, uma vez que os textos freudianos usualmente entendidos como “sociais” especificam e aprofundam aspectos da metapsicologia extremamente pertinentes clinicamente. Isolados numa espécie de psicologia social psicanalítica, redundam em um entendimento pobre do social (Costa, 1989).

Mas além de reconceber os textos sociais freudianos como prolongamentos da sua metapsicologia, com elevada relevância clínica, para efetivamente renovar a incidência da psicanálise sobre a psicologia social de uma maneira profícua, é imprescindível também fazer o caminho inverso e situar no âmago da clínica e da metapsicologia o que poderia ser uma psicologia social psicanalítica propriamente dita.

A teoria psicológica freudiana abarca o funcionamento do psiquismo, não circunscrito ao individual. O social da psicologia psicanalítica não é uma extensão do saber sobre o psiquismo individual ao social. É a psicologia de cada sujeito que já é constitutivamente social, embora por ser meramente psicologia não precise nem tenha como dar conta de toda a verdade do social.

Logo, insista-se, a contribuição mais efetiva da psicanálise para a psicologia social está onde não se a supõe: na metapsicologia e na clínica.

Embora a psicanálise tenha se revelado mais fértil e criativa nas suas aplicações que não se dissociaram da clínica, habitualmente os psicólogos sociais não levam isso em conta. Muitas vezes, reduziu-se a utilização da psicanálise em psicologia social a uma chave hermenêutica capaz de atribuir significados a fenômenos sociais, sem dar maior atenção ao seu potencial para fornecer modelos de intervenção e de transformação social, nem submeter às especulações assim obtidas a nenhuma forma de controle empírico.

Deste modo, perde-se o contato com o vivido, que fortaleceu a psicanálise e a desenvolveu noutras áreas da psicologia.

A revitalização da contribuição da psicanálise para a psicologia social poderá advir não dos textos tradicionalmente entendidos como a psicologia social freudiana, mas do seu núcleo clínico e epistemológico. É fundamental levar a sério desenvolvimentos técnicos e teóricos que fazem sobressair a dimensão social, como por exemplo, a noção winnicottiana de fenômeno transicional (Winnicott, 1971/1975, 1988/1990) e a insistência lacaniana na dimensão semiótica da matéria subjetiva (Lacan, 1966, 1981), importantes para o desenvolvimento da teoria e da clínica psicanalíticas numa direção tendente a superar a dicotomia entre interior e exterior. Tais desenvolvimentos propiciam subsídios notáveis para o estabelecimento de uma psicanálise que supere os limites da sua aplicação individual e se constitua em plataforma para o seu relançamento no campo dos estudos e das intervenções em psicologia social.

Nesta oportunidade, vai-se considerar especificamente o conceito de significante.
Para Lacan, qualquer interlocutor concreto só se constitui e tem lugar relativamente a uma alteridade fundamental, constituinte do $e u$. Por sua vez este, enquanto sujeito, não é da ordem da chamada interioridade, circulando social, cultural e temporalmente.

Sendo assim, não se vê por que o artifício da clínica liberal, ele mesmo até certo ponto um produto socialmente datado, deva impor-se como única possibilidade de intervenção psicanalítica, nem mesmo que seja o caso de ampliar e "adaptar” o seu exercício na forma do atendimento a grupos, técnica e teoricamente decalcados do modelo de atendimento individual.

A psicologia do grupo é um caso particular de um potencial de funcionamento drasticamente coletivo.

Os significantes circulam socialmente, atingindo de modo singular cada sujeito, mas inter-relacionando e estabelecendo laços entre um número enorme de pessoas. Delineiam campos de identidade e de diferenças, cimentam laços culturais e intergeracionais, inscrevem a possibilidade de rememorações intra e intersubjetivamente dadas e criptografam a memória de glórias e de misérias. Guardam gozos, lutos e conflitos.

A marca significante não é propriedade privada de um ego ou de um grupo de egos acionistas. Está na rua, em públicos segredos íntimos, em histórias pessoais que são atualizações de memórias históricas mais ou menos maltratadas e, por isso, o inconsciente não precisa ser concebido em termos estritamente psíquicos nem individuais. Abriga-se num horizonte que também é intrinsecamente social, cultural e histórico.

Em "Fonction et champ de la parole et du langage em psychanalyse”, publicado em 1966, na coletânea Écrits, Lacan vai dizer que o inconsciente é uma parte em falta num discurso concreto e essa parte em falta pode ser mapeada pelas partes efetivamente proferidas. Sempre expressa alguma verdade do sujeito, que deixa de ser referido a uma interioridade psíquica, pois os signos circulam socialmente (dando forma tanto a subjetividades, quanto a “mentalidades” coletivas). É parte do discurso concreto, transindividual, em falta. Além de não dito, ou mal dito, algum ou vários dos seus significados não estão disponíveis para o sujeito. Cifram-se e decifram-se no processo da sua dicção (não necessariamente feita com os meios da linguagem verbal, pois dizer não se resume a falar).

A narrativa do inconsciente pressupõe interlocução. Embora possa descrever ou re-elaborar uma memória pessoal, os meios a que se prende são públicos (signos) e dialógicos. Nada indica que se prestem à exclusão do social, por lhes ser inerente a dimensão de empreendimento coletivo.

É surpreendente que não se tenha extraído desta definição semiótica do inconsciente as conseqüências óbvias para uma re-concepção da psicanálise em termos sociais, uma vez que Lacan deixa de entendê-lo como representação inconsciente privada (inacessível à consciência, mas norteadora da ação do sujeito, o que para ele é contraditório e inadmissível), e passa a pensá-lo como feito de significância, efeito de significantes (Bairrão, 2003a).

A idéia freudiana de toda a psicologia ser eminentemente social é retomada de uma maneira não presa ao psiquismo, abordada concretamente pela forma, pública, da linguagem. 
E uma vez que o universo sígnico que interessa à psicanálise e se encarna nas existências humanas não é distinto do presente na sociedade e na cultura, a psicanálise pode contribuir para resolver dilemas com os quais o investigador interessado no social freqüentemente se depara - dicotomias como singular e universal, pessoal e coletivo, particular e genérico, encontram um modelo conveniente à sua superação. $\mathrm{O}$ mais íntimo processa-se com os elementos mais públicos. $\mathrm{O}$ dentro mostra-se fora e o fora encontra-se dentro. O que atinge muitos é crucial para um, o que afeta um circula em todos.

Torna-se viável desenvolver modelos de investigação e de intervenção psicológicas que não se restrinjam ao psíquico individual, mas também não se reduzam a generalidades sociológicas.

Tais desenvolvimentos são importantes, não apenas pela ampliação do alcance social do trabalho do psicólogo, mas principalmente por abrirem a possibilidade de se cumprir uma vocação ética essencial ao trabalho em psicologia social, numa perspectiva psicanalítica: a de restituir a escuta da voz de sujeitos sociais para eles próprios. Pouco valor tem o tratamento se o sujeito continuar sem fala própria. O que é tratar, se não devolver ao outro a dignidade de (se) dizer?

Algumas psicologias tomam o comportamento como objeto de estudo do psicólogo, ou de outro modo definem um objeto, segundo o modelo das ciências duras: a psicologia poderia se propor como objeto o comportamento (ou um equivalente) e adotar procedimentos metodológicos semelhantes aos das chamadas ciências da natureza. Outras reconhecem a especificidade do seu objeto como portador de sentido. Propõem procedimentos e metodologias hermenêuticos (numa acepção lata) para lidar com o humano. Não visam descrever uma suposta coisa comportamental, mas compreender o sentido das ações humanas, recorrendo a diversas chaves de interpretação. Muitas psicanálises atêm-se a este plano.

Porém, além de admitir que o seu objeto comporte sentido, a psicologia pode (deve) reconhecer que ele é produtor de sentido (mesmo que o desconheça) e passar a tratá-lo como sujeito.

A psicanálise pode satisfazer este requisito. Permite ao sujeito ser autor, por se centrar na enunciação, e não no dado já significado, no fato consumado. Não há necessidade de reduzir a prática do psicanalista a uma pedagogia paternalista, que recondicione as interpretações e entendimentos do paciente à sua teoria (Nathan, 2000).

A psicanálise proporciona meios para, mais do que atribuir significados, resgatar nas coisas da realidade cultural a sua dimensão enunciativa, situando, interpelando e responsabilizando sujeitos sociais. Tal psicanálise, beneficiada por aprofundamentos teóricos desenvolvidos especialmente no âmbito da etnopsiquiatria francesa (Devereux, 1951/1998, 1967/1977, 1970/1977; Nathan; 1994; Nathan \& Hounkpatin, 1996) pode ser mais do que um poderoso instrumento hermenêutico, capaz de levar o psicólogo a atribuir significados aos fenômenos sócio-culturais, e reconceber-se como um instrumento heurístico, empiricamente posto ao serviço do resgate de vozes coletivas.
Em conformidade, o que aqui se propõe é a utilização da psicanálise como método capaz de resgatar os sentidos dessas vozes, e não como um sistema de proposições teóricas sobre a natureza humana e o psiquismo, uma vez que não se visa substituir ou traduzir etnoteorias por concepções embasadas naquelas, mas tão somente recuperar o inconsciente, ou seja, partes de discursos concretos transindividuais não ditas, nos próprios termos e contextos em que se formulariam.

Conceitos psicanalíticos como significante e fenômeno transicional, desenvolvidos em âmbitos em que a disciplina jamais perdeu o vínculo com a clínica, abrem perspectivas para a pesquisa do imaginário social. São especialmente úteis para a verificação da possibilidade acima apontada num âmbito cultural e socialmente relevante que não pode ser reduzido a um modelo de funcionamento grupal (o estudo do transe de possessão em práticas religiosas brasileiras sincréticas), por envolver uma interpretação cultural da totalidade da realidade e, portanto, ressignificar o entendimento de pessoa e de todas as coisas.

\section{Atualidade do interesse no estudo do transe e do sincretismo para a psicologia}

O transe e o sincretismo, tão presentes nas religiões afrobrasileiras, são uma boa oportunidade para verificar esta hipótese. Permitem testá-la no âmbito em que o imaginário social se apresenta reflexivo (a vários títulos) e claramente enunciativo, ou seja, em cultos extáticos como a umbanda e a jurema.

Tão presente na realidade cultural brasileira, o imaginário religioso popular constitui-se numa linguagem em que se cifram negociações e conflitos social e penosamente enunciados, os quais ao mesmo tempo reportam uma memória social mal dita e se singularizam em dramas pessoais.

O resgate do sentido desses ditos é possível mediante o registro de músicas rituais e à feitura de entrevistas com religiosos em estado de transe.

Fazendo-o, obtêm-se subsídios para o conhecimento da realidade social e psíquica brasileira, bem como para o desenvolvimento de estratégias éticas para o trabalho com comunidades e para a consolidação de um método empírico de estudo da alteridade.

Tal resultado não deve surpreender, uma vez que esses ritos não são junções irrelevantes de elementos confusa e arbitrariamente misturados entre si.

O encadeamento dos objetos e atos rituais, a escolha e montagem do cenário ritual, a combinatória das frases, invocações e emprego de símbolos escritos, cantados e gestuais, e mesmo o recurso a materiais como flores, pedras e bebidas (por exemplo), podem ser entendidos como uma enunciação cujo alcance e cabal significação, em larga medida, não são acessíveis imediatamente à consciência dos participantes, o que para um observador desavisado pode causar a impressão de “confusão” ou "ignorância”. Porém, trata-se de um fato normal num contexto cultural em que há uma clara distinção e freqüente oposição entre o sujeito agente da enunciação (freqüentemente um espírito ou um ser divino) e o sujeito (psíquico e humano) que anima ou serve de veículo ao enunciado. Nos cultos de possessão, como em outras formas de 
experiência religiosa, a linguagem, ou mais precisamente o sujeito suposto ao ato significante, o autor, o mais das vezes não se confunde com o indivíduo que anima o ato enunciativo (Keane, 1997).

A distinção entre sujeito da enunciação e sujeito do enunciado, adotada pela psicanálise lacaniana, é útil para dar conta de processos como este, sem entrar no mérito de validar ou invalidar o tipo de experiência e de representação da realidade pressuposto pela idéia de possessão, meramente se atendo aos tipos de estruturas e concepções de sujeito vigentes neste tipo de universo religioso (os cultos de possessão).

Desde que também se leve em conta que o significante não se restringe ao verbal, a idéia de um sentido à revelia do enunciado conscientemente (este último, o sentido acessível aos integrantes do culto), mas mapeável discursivamente, soma-se às indicações anteriores para perfazer um rol de instrumentos psicanalíticos bastante útil para o resgate do inconsciente no transe.

Recorde-se que aqui se leva em conta um entendimento do inconsciente que não mais o toma como atinente a uma realidade psíquica, mas apenas como parte não dita num discurso concreto, transindividual. Ou seja, nada se afirma nem se nega sobre a natureza objetiva do sujeito, de maneira a permitir que quaisquer pressuposições a esse respeito, até mesmo as que referem a instância enunciante a seres espirituais e extrínsecos ao indivíduo, possam ser escutadas no que possam revelar acerca do enunciante, sem se atrapalharem com juízos sobre a natureza do outro pressuposto pelas formas de estruturação do sujeito correlatas da possessão.

Como o inconsciente não mais é concebido como uma parte da realidade psíquica individual inacessível à consciência, também o sujeito, resumido a uma posição enunciativa a ser compreendida e interpretada no contexto de enunciação, poderá ser entendido como um fenômeno histórico ou memória social representada coletivamente e elaborada com recursos culturais próprios. Nisto reside um dos principais interesses do estudo do transe de possessão para a psicologia: permite a escuta do não dito, do inconsciente, em narrativas que conjugam tanto a singularidade de um porta-voz individual e de sua comunidade com um patrimônio simbólico histórico e coletivo que não pode adequadamente equacionarse nos termos de uma psicologia de grupo.

É reconhecível a diferente origem e os diversos tempos de aquisição dos elementos utilizados nas composições significantes perfeitas no âmbito do culto e é essa intrínseca e transparente historicidade dos fenômenos de linguagem envolvidos na possessão que muitas vezes vai despertar estranheza e será reportada, às vezes pejorativamente, como sincretismo.

Embora o olhar culto possa enxergar, nos rearranjos sincréticos restos de produtos culturais perdidos das suas origens, ao fazê-lo impede-se de se abrir ao sentido enunciativo presente na recombinação efetuada.

Na contramão desse risco, a idéia de dar ouvidos ao transe e às suas manifestações tem uma dupla origem: motiva-se da insatisfação com a prática psicanalítica habitual, inábil em interpelar coletividades, e da aposta na possibilidade de, a par- tir da psicanálise, formular meios teóricos e metodológicos capazes de resgatar a participação do sujeito social na direção dos processos que lhe dizem respeito (inclusive e principalmente incluí-lo na autoria do conhecimento a ele pertinente).

Talvez não haja uma única razão para o pouco interesse manifestado por enquanto no estudo do transe por parte da psicologia brasileira, somando-se fatores que vão da dificuldade epistemológica em reconceber o psiquismo como dado social, à dificuldade da nossa sociedade, da qual os pesquisadores fazem parte, em reconhecer-se herdeira da humanidade de antigos escravos e "selvagens".

É fato que freqüentemente as elites brasileiras, tanto as chamadas conservadoras quanto as ditas progressistas, unemse em lastimar o "atraso" e a pobreza (inclusive cultural) do país (Brumana \& Martinez, 1991). A parcela progressista empenha-se em "salvar" da miséria, física, moral e intelectual, a massa da população, mas fundamentalmente, implicitamente, está de acordo com os conservadores quanto à "superioridade" dos seus valores e crenças sobre os populares e a sua cultura "pobre”. Muito raramente lhe ocorre que a diferença cultural possa expressar uma riqueza e que, para além do seu julgamento, objetivamente se resguarde um patrimônio cultural pujante e digno. Logo, age no sentido de suprir carências (a carência é sempre do outro) e fornecer interpretações e soluções, permanecendo surda ao que na realidade humana sobre a qual se debruça já é opinião, apelo, enunciação.

Deste modo, inadvertidamente, há o risco social do conhecimento acadêmico, apanágio das elites, inserir-se numa repetição inadvertida do estereótipo ficcional do "bom" senhor de escravos, incompatível com atitudes realmente transformadoras do contexto sócio-cultural vigente.

Principalmente, a crítica aos processos de recriação cultural denominados de sincretismo estabelecida por setores politicamente engajados da elite intelectual é caracteristicamente um procedimento de tipo colonial (ampliando o uso do termo à acepção de colonização de mentes): atribui um significado a fenômenos culturais e práticas sociais, como se elas não tivessem condições de se pensarem a si mesmas.

O estudo psicológico das manifestações culturais ditas sincréticas permanece superficial e é posto a serviço de interesses alheios aos dos principais interessados se o fenômeno a interpretar e o sujeito da interpretação não forem vistos como dois lados da mesma moeda, como se essencialmente o próprio sincretismo não fosse em si mesmo uma interpretação, implicadora de sujeitos, e a priori já estivesse definido quem fossem os bem e os mal pensantes (deste modo, é praticamente impossível evitar certo tipo de autoritarismo "bondoso").

O psicólogo, sob pena de se arrogar o papel de juiz da correção da cultura popular, não pode proceder assim. Deve saber que naquilo que se enxerga, ou não se enxerga, há um componente não eliminável, que é o olhar de quem vê.

Esta implicação da subjetividade do pesquisador nos resultados da sua pesquisa não é a menor advertência e contribuição da psicanálise para a pesquisa social e psicológica, não tendo passado despercebida a autores que se tornaram clássicos (sempre atuais), como Devereux (1967/1977). 
Entretanto, o fato é que um fenômeno rico e variado, cheio de estratégias e de recursos ressignificadores e assinaladores de práticas de resistência cultural à subjugação, muitas vezes foi visto como sinal do contrário, indício de pobreza material e de espírito, e marca da efetividade de uma opressão pela qual os que a vêm se eximem, por não se reconhecerem no que fazem com os seus olhos, permanecendo cegos ao fato de que a sua maneira de ver, o modo como abordam o assunto, reitera a dominação que fantasiam combater: não se enxergam, só vêm processos sócio-históricos que remontariam a um passado aparentemente alheio à sua atitude atual e, portanto, à sua responsabilidade.

Este desaire reproduz-se nitidamente em opiniões doutas, persistentes em acusar os populares de incapacidade em preservar uma pureza cultural, idealizada - tese desatenta exatamente ao fator contrário, a enorme capacidade do povo em usar, refletir, elaborar, preservar e recriar o que é seu, evidenciada, por exemplo, pelo sincretismo.

Como nenhum raciocínio em termos de pureza e de mistura de raças e de culturas se justifica, é possível entender o sincretismo como um recurso inteligente, uma capacidade de metabolizar, re-elaborar e salvaguardar a própria identidade e de presentificá-la em novos contextos.

A imagem reconstruída imaginariamente de uma pureza original é fantasiosa e, ao contrário do que se pretende, pouco útil do ponto de vista da elaboração histórica e psíquica de uma identidade (pessoal e coletiva). Sempre põe no passado, mais ou menos perdidas, as marcas de uma identidade, quando se poderia lidar com elas por meio da sua repetição contextualizada no presente, sem a ilusão de estar extraindo gotas de um paraíso perdido.

Além disso, esse tipo de visão permanece alheio à consideração de uma temporalidade intrínseca e peculiar ao imaginário religioso, inconfundível com a linearidade cronológica (Corbin, 1971), o que impossibilita uma apreciação mais fina e fiel dos fenômenos sincréticos.

Conforme bem assinala Ferretti (1999), a crítica ao sincretismo, mais engajada do que intelectualmente bem constituída, é um fenômeno periférico aos setores (religiosos) que o cultivam, possivelmente mais vinculada a usos das religiões afro-brasileiras do que ao respeito à vivência profunda das apresentações do mundo e elaboração e aplicação de categorias que nelas se formulam.

\section{Psicanálise e pesquisa de campo}

A psicanálise, sempre atenta ao desejo do outro e à implicação do analista na sua análise, poderia contribuir para mudar esse panorama?

Aposta-se que sim. Conforme foi esmiuçado anteriormente, a noção lacaniana do inconsciente como social e semioticamente dado permite recuperar a dimensão histórica e coletiva do psiquismo (Bairrão, 1999). O sincretismo é uma oportunidade ímpar para passar da crítica epistemológica à noção psicológica de representação psíquica inconsciente a um emprego heurístico positivo dos resultados negativos a que Lacan havia sido conduzido no curso dessa crítica (Bairrão, 2003a).
Perante a tentação de reduzir a mentalidade popular, o transe e as elaborações sincréticas a raciocínios confusos ou sem sentido, é preferível adotar-se o mesmo procedimento de Freud em relação às formações do inconsciente: sempre a aposta em outro sentido, nunca no sem sentido.

Outra regra metodológica útil e recomendável é não presumir que a verdade do fenômeno (imaginário e religioso) possa explicitar-se em outra ordem que não aquela em que efetivamente se apresenta. Sempre que o sujeito do transe se nomeia como relativo a uma dimensão epifânica, nunca se presuma poder descrevê-lo melhor escamoteando a sua pertença ao âmbito do sagrado. Como o intuito é evidenciar a enunciação do sujeito social em si mesma, e não significados que lhe possam ser atribuídos, se ele fala do sagrado e, portanto, se apresenta como sujeito religioso, não se pode desautorizar essa fala.

Conseqüentemente, deve-se renunciar à tentação de fazer traduções. Trocar, por exemplo, explicações nativas, por freudianas ou marxistas. A entrada da psicanálise não pode ser esta (atribuir sentido), mas a de revelar a voz de sujeitos, e para isso é fundamental aprender e apreender a sua linguagem e verificar o que com ela se enuncia, nos próprios termos em que é referido (e não colonizá-la por outros referenciais).

Isso implica suspender o juízo quanto à realidade dos fenômenos narrados e em abolir o uso dos termos certo e errado.

\section{Escuta participante}

Algumas pesquisas de campo (por exemplo, Bairrão, 2002; 2003b) parecem corroborar o potencial, heuristicamente útil, do modelo proposto; além de contribuírem para auxiliar a refletir os desafios metodológicos vinculados à problemática da observação participante (Malinowsky, 1922/1976; Durham, 1997) e especialmente ao seu sentido em psicologia. No seu âmbito, o transe tem merecido especial atenção por nele, imediatamente, o mesmo (o Outro!) interpelar como sujeito.

Pelo menos no transe, indiscutivelmente, a interpelação é literalmente consubstancial ao sujeito que é objeto de estudo: ele mostra-se enunciante, fala e fala-nos de nós! Nessa medida, imediatamente se é participante. O pesquisador é interpretado e incluído no lugar de consulente.

No rol dos que consultam os guias, muitos buscam consolo para dores morais ou físicas, ou soluções para amores. O pesquisador quer saber como eles se definem e como apresentam os seus cavalos. O que pede aos espíritos é que lhe narrem as suas histórias. Mas atender este pedido, fundamentalmente, não se diferencia de cuidar de mais alguém que os procura. Insere-se na lógica do atender um consulente, do cuidado para com um filho.

É duvidoso que esta imediata inclusão seja basicamente uma estratégia de envolvimento e sedução (como se poderia pensar), destinada a comprometer a capacidade de observação e de análise. O fenômeno só pode mostrar-se da maneira como acontece, revela-se dialogicamente, executando os atos que são a sua natureza. O observador é sempre um tu a ser cuidado no seu ser (e nunca apenas um profissional no desempenho de um papel). 
Furtar-se a este tipo de tratamento impediria o aprofundamento da análise, não por uma recusa do encantado em fornecer informações, mas pela expectativa do pesquisador, descabida, de que aquele subsistisse fora do estilo de se revelar que lhe é inerente. A participação como consulente é consubstancial ao fenômeno.

Neste caso, ou talvez sempre em psicologia, o método de observação participante manifesta-se como uma participação observante. No caso, uma escuta participante (dada a interpelação e a estrutura dialógica do fenômeno, a participação revela-se um instrumento de refinamento da audição).

Os níveis de revelação do fenômeno são proporcionais ao modo de abordá-lo e a escuta participante é também uma propedêutica ao deciframento das semioses em jogo. $\mathrm{Na}$ umbanda ressoam as vozes da história e de histórias, coletivas e pessoais, em uníssono. O morto vive nos corpos, nos ritmos, nas imagens, nos cânticos e nos aromas (se não metafísica, pelo menos metaforicamente).

Muitas vezes é inútil encontrar um significado verbal por trás de um gesto ou procedimento, significantes. Respostas em forma ritual, gestual, em linguagem mítica, longe de serem fugas ao proposto, são a preciosa forma e a maneira exata de responder às indagações. Se houver deficiência ou resistência, é do lado da sagacidade hermenêutica do pesquisador.

Uma vez havendo a intenção sincera de pôr a psicologia ao serviço do outro real - o que implica em não se sobrepor à voz popular, mas dar-lhe alcance, amplificá-la - e dado que a aposta de que se parte se prende à idéia da possibilidade de resgatar sentidos cifrados nas elaborações religiosas populares, que restituam riquezas ocultas e dignidades enxovalhadas, o critério de adotar procedimento que permita uma revelação mais profunda do fenômeno, o respeito, e o cuidado em prestar ouvidos a todos os modos dele se contar (e especialmente aos menos óbvios) parecem recomendar o método seguido.

\section{Agradecimentos}

Este trabalho é profundamente devedor do acolhimento e do apoio de comunidades umbandistas (cujos nomes omito, levando em conta a solicitação de algumas e a indiferença das demais quanto à sua divulgação). Apresento os meus agradecimentos a todos os que o tornaram possível.

\section{Referências}

Bairrão, J. F. M. H. (1999). Santa Bárbara e o divã. Boletim Formação em Psicanálise, 8(1), 25-38.

Bairrão, J. F. M. H. (2002). Subterrâneos da submissão: sentidos do mal no imaginário umbandista. Memorandum: Memória e História em Psicologia, 2, 55-67. Disponível: http://www.fafich.ufmg.br/ memorandum/artigos02/ bairrao01.htm

Bairrão, J. F. M. H. (2003a). O impossível sujeito: implicações da irredutibilidade do inconsciente. São Paulo: Rosari.

Bairrão, J. F. M. H. (2003b). Raízes da jurema. Psicologia USP, 14(1), 157-184.

Brumana, C., \& Martinez, E. (1991). Marginália sagrada. Campinas: Editora da Universidade Estadual de Campinas/Unicamp.

Corbin, H. (1971). L'homme de Lumière dans le soufisme iranien. Paris: Présence.

Costa, J. F. (1989). Psicanálise e contexto cultural: imaginário psicanalítico, grupos e psicoterapias. Rio de Janeiro: Campus.

Devereux, G. (1977). De la ansiedad al método en las ciencias del comportamiento (Felix Blanco, Trad.). México: Siglo Veintiuno. (Texto original publicado em 1967)

Devereux, G. (1977). Essais d'éthnopsychiatrie générale (3 $3^{\underline{a}}$ ed., revista). Paris: Gallimard. (Texto original publicado em 1970)

Devereux, G. (1998). Psychotérapie d'um indien des plaines: réalité et rêve (Françoise de Grusson, Trad.). Paris: Fayard. (Texto original publicado em 1951)

Durham, E. (1997). A pesquisa antropológica com populações urbanas: problemas e perspectivas. In R. Cardoso (Org.), A aventura antropológica: teoria e pesquisa (pp. 17-37). São Paulo: Paz e Terra.

Ferretti, S. F. (1999). Sincretismo afro-brasileiro e resistência cultural. In C. Caroso \& J. Bacelar (Org.), Faces da tradição afro-brasileira: religiosidade, sincretismo, anti-sincretismo, reafricanização, práticas terapêuticas, etnobotânica e comida (pp. 113-130). Rio de Janeiro/Salvador: Pallas/CEAO.

Keane, W. (1997) Religious language. Annual Review of Anthropology, 26, 47-71.

Lacan, J. (1966). Écrits. Paris: Seuil.

Lacan, J. (1981). Le Séminaire Livre III: Les Psychoses. Paris: Seuil.

Malinowski, B. K. (1976). Argonautas do Pacífico ocidental: um relato do empreendimento e da aventura dos nativos nos arquipélagos da Nova Guiné Melanésia (A. P. Carr \& L. A. C. Mendonça, Trad.; E. R. Durham, Rev.; Coleção Os Pensadores, vol. 43). São Paulo: Abril Cultural. (Texto original publicado em 1922)

Nathan, T. (1994). L'influence qui guérit. Paris: Odile Jacob.

Nathan, T. (2000). L'héritage du rebelle: le rôle de Georges Devereux dans la naissance de l'éthnopsychiatrie clinique en France. Ethnopsy - Les Mondes contemporains de la Guérison, 1, 197-226.

Nathan, T., \& Hounkpatin, L. (1996). La parole de la forêt initiale. Paris: Odile Jacob. Winnicott, D. W. (1975). O brincar e a realidade (J. O. Aguiar Abreu e V. Nobre, Trad.). Rio de Janeiro: Imago. (Texto original publicado em 1971) Winnicott, D. W. (1990). Natureza humana (D. L. Bogomoletz, Trad.). Rio de Janeiro: Imago. (Texto original publicado em 1988)

\section{Nota}

${ }^{1}$ Este trabalho contou com apoio da FAPESP (Auxílio à Pesquisa) e do CNPq. Uma versão preliminar foi apresentada oralmente no IV Simpósio da Associação Brasileira de História da Religião (O Estudo das Religiões: Desafios Contemporâneos, São Paulo, PUCSP, 22 a 24 de Maio de 2002).

José Francisco Miguel Henriques Bairrão, doutor em Filosofia pela Universidade de Campinas, é professor e pesquisador de Psicologia Social no Departamento de Psicologia e Educação da Universidade de São Paulo, em Ribeirão Preto. Endereço para correspondência: Departamento de Psicologia e Educação, FFCLRP/USP; Campus de Ribeirão Preto; Avenida dos Bandeirantes 3900; Ribeirão Preto, SP; CEP: 14040-901. Tel.: (16) 3602-3808. E-mail: jfbairrao@ffclrp.usp.br 